Solutions, not scapegoats

\author{
Scientific misconduct may be more prevalent than most researchers would like to \\ admit. The solution needs to be wide-ranging yet nuanced.
}

M any researchers would like to believe that scientific misconduct is very rare. But news reported in this issue (see page 969), and the survey results reported by Sandra Titus and her colleagues on page 980 , challenge that comfortable assumption. Titus's team found that almost $9 \%$ of the respondents in their survey, mainly biomedical scientists, had witnessed some form of scientific misconduct in the past three years, and that $37 \%$ of those incidents went unreported.

The results suggest a research climate in which scientific misconduct, although uncommon, is certainly not an anomaly. Titus et al. outline a number of measures to address this situation, including better protection for whistleblowers, and promotion of a 'zero tolerance' culture in which scientists have just as much responsibility to report others' misconduct as they have for their own behaviour.

However, although these proposals have much to recommend them, they are, at best, a beginning. A more radical change of perspective may be in order - one in which misconduct is no longer viewed as problem that can be solved by identifying and banishing a few unethical individuals. Instead, the problem calls for approaches that are both more nuanced and more far-reaching.

Consider, for example, that not all cases of misconduct are equally egregious, and not all perpetrators deserve to be branded as cheaters for the rest of their careers. There is often room for honest mistakes and differences of opinion. Yes, institutions should develop strong guidelines for what is and is not permissible, but officials should also have the flexibility to compare individual situations to these guidelines, and to develop unique solutions as needed. In some cases - for example, a young researcher who simply yielded to temptation once - a system of warnings might be used to both correct the problem and educate the researcher. Within individual labs, moreover, airing complex matters - such as decisions about when data can be justifiably excluded from analysis, or how images can be ethically adjusted to improve their quality — may reduce the chance that any single investigator's decision will later lead to accusations of misconduct.

Meanwhile, misconduct investigations all too often focus solely on an individual offender, and fail to diagnose the environment that has allowed misconduct to flourish. Instead, institutions should seize the opportunity to learn from the experience, and to address the bigger questions. For example, did the atmosphere in the lab create the pressure to cut corners? Or did the intensity of the tenure chase contribute? One way to address such questions might be through internal departmental discussions, in which everyone is free to admit mistakes, and discuss how to fix the problems instead "Investigations often fail to diagnose the environment that has allowed misconduct to flourish." of apportioning the blame.

More-formal misconduct investigations may need to be kept private, as a necessary safeguard to protect the falsely accused. Nonetheless, institutions can and should share the lessons they have learned from the process. Officials at an institution may learn, for example, that mentoring needs to be improved, or that their system for reporting misbehaviour is flawed. Unfortunately, some institutions may instead feel pressure to bury or cover-up their findings for fear of negative press. But to do so is to gain a short-term reprieve at the expense of long-term loss: such institutions will only be doomed to repeat past mistakes.

This means turning attention away from scapegoats, and focusing on solutions.

\section{Change in the weather}

\section{A renewed push for scientific research into weather-modification technologies is long overdue.}

n the 1956 movie The Rainmaker, Burt Lancaster plays a con man catering to the dreams of spinster Katharine Hepburn. And while both stars triumph in the end - the rain does fall, and she comes out of her shell - the implication remains that rain-making is little more than a scam.

Today's rain-makers struggle with their own credibility issues. They do have well established methods for seeding clouds with silver iodide crystals, which in most cases bolster precipitation by a small but significant amount (see page 970). That's enough to make the effort worthwhile for communities looking to bolster the snowpack on which they rely for water in summer, or to target rainfall over an agricultural area rather than a neighbouring one that is barren.

Yet weather-modification supporters face a perceived negative bias in the scientific community. For instance, a 2003 report from the US National Research Council publicly doubted whether weather-modification techniques work at all, although it did call for more investment in the field. There has yet to be the definitive experiment that settles exactly how well cloud seeding - or other weather-modification techniques, such as diverting fog or suppressing hail - works (or not).

Part of the scepticism is due to the field's chequered history. The field was born in a blaze of enthusiasm in the General Electric Research Laboratory in New York in 1946, when researchers began dreaming of weather modification on a grand scale — showering areas with rain and redirecting lightning strikes. But decades passed with little concrete progress; even the United States' wonderfully named Project Stormfury, which aimed to weaken hurricanes before they reached land, fizzled out in 1983. And basic questions remain unanswered regarding cloud and 
atmospheric physics, such as the influence of air-pollution aerosols.

As is the case in so many areas, the issues with weather modification boil down partly to an uneven allocation of resources. Some countries, such as Israel, have bucked the trend; the country's early experiments with cloud seeding identified the many scientific unknowns that remain, and the government has continued to fund ongoing work to understand those factors better. Other countries, such as the United States, have simply given up; the most promising experiment in America is run not by the federal government but by the state of Wyoming, which is spending nearly US\$ 9 million on a five-year series of cloud-seeding experiments evaluated by experts from the National Center for Atmospheric Research. That's the type of targeted and rigorous study that needs to be done in weather modification, but it took Wyoming to do it.

Elsewhere, plenty of money is flooding into the field, but on the wrong methods. There is little doubt that China's massive weathermodification undertaking has huge appeal for its rain-starved farmers. But most of the money goes on the operational costs of running technologies that have yet to be validated by science. China has the resources and the willpower to lead the world in weather-modification research, but has not yet stepped fully into that role. One promising move, however, is its newly established centre for weathermodification research.

If researchers could improve their understanding of weather modification, it might then be possible to tackle some of the larger legal and political issues. What happens, for instance, when one country wrings excess water out of a cloud before it drifts over a similarly parched neighbour? How does one engage cross-border negotiations on atmospheric rain, when terrestrial water (in aqueducts and rivers) itself is so contentious? Who actually owns the weather?

The stakes are high, as weather modification is one of those areas in which science can have an immediate and obvious benefit for society. It's long past time to invest modest funds in the basic understanding of it. Otherwise, the world's rain-makers may find themselves considerably less successful than Burt Lancaster.

\section{Supporting the future}

\section{... but the European Research Council's success is undermined by practices beyond its control.}

or most of the past four centuries, Europe has been one of the world's great crucibles of revolution - the place where artists, scientists, philosophers and industrialists overthrew the medieval order and pioneered a new age of democracy, technology and individual initiative. And yet, thanks to lingering cultures of hierarchy and institutional rigidities, continental Europe today is a surprisingly difficult place to be a young scientist. Witness the way so many of those young minds continue to flock westward, either to Britain, the least hidebound European country for young scientists, or to the even greater opportunities in the United States. The few institutions on the continent that have managed to empower young scientists - a notable example being the European Molecular Biology Laboratory in Heidelberg, Germany - remain the exception rather than the rule.

Thus, in a week when an Irish referendum has plunged the European Union into new paroxysms of constitutional uncertainty, there is reason to celebrate a new organ of the European Union that is taking a notable step in the right direction: the European Research Council (ERC), founded early in 2007. The ERC's founders deserve great credit for their determination to keep it independent of political and economic considerations, so that it can award its grants on the basis of scientific excellence alone. The ERC has now done just that, giving out substantial money - with much more to come - to young scientists who can take those funds to a host institution of their own choice (see page 975). A sign of the council's success is that some countries have set up special funding schemes to support high-rated applicants who, because of the massive oversubscription, failed to get ERC funding. Credit, therefore, should go to Chris Patten, the chancellor of the University of Oxford, who chose the initial council members; to Ernst-Ludwig Winnacker, the ERC secretary- general who is responsible for its relations with the European Commission; and to council president Fotis Kafatos, who is responsible for delivering its goals.

The prestige of the ERC makes it relatively easy to defend; its champions will have little difficulty in obtaining vocal, high-level support if its drive for unmitigated excellence is threatened. Indeed, the avoidance of this threat - so far - has been one of its most notable achievements. It would have been easy for countries new to the European Union, many of which have relatively weak scientific track-records, to resist the evident trend for ERC fundees to take their grants to host institutions in already dominant European countries. But it seems to be widely recognized across Europe that the goal of scientific excellence should trump nationalistic considerations. Élite diasporas can even be viewed as an investment: at least some of the young émigrés will eventually return to their own countries.

None of this, however, is any excuse for complacency. Pressure to hijack the ERC agenda for political ends can be expected from time to time, and must "The goal of scientific excellence should trump nationalistic considerations." continue to be firmly resisted. And even more important in the meantime is the need to streamline the European Commission's remarkably inflexible bureaucratic arrangements for ERC awards, which threaten to undermine the council's success. Despite doughty championship of the ERC by the research commissioner Janes Potočnik, and the council's quasi-independent status, grantees are being treated like contractors. This means that both the amount and terms of their funding are subject to negotiations that can drag on for months, which makes planning impossible. It also means that talented young scientists can find more ready terms in the United States and vote with their feet - as has already happened in one or two cases.

Thus, a key priority for those in a position to make a difference should be to change either the implementation or the constitution of the ERC, both to preserve and extend what has been achieved so far, and to stop defeat being snatched from the jaws of victory. 